\title{
2 Virtual Power Plants and Their Prospects
}

\author{
Lucas Feksa Ramos ${ }^{1}$ * and Luciane Neves Canha ${ }^{2}$ \\ 1 Department of Electrical Engineering, Federal University of Rondônia, Porto Velho 76801-059, Brazil; \\ feksa@unir.br \\ 2 Department of Electromechanics and Power Systems, Federal University of Santa Maria, Santa Maria \\ 97105-900, Brazil; lucianecanha@ufsm.br (L.N.C.) \\ * Correspondence: lucasfeksaramos@gmail.com (L.F.R.)
}

\begin{abstract}
This article presents an in-depth review of Virtual Power Plant (VPP), its organization in the energy system and its prospects in the face of the promising future of the increasing bidirectional complexity exposed in the current scenario. A new paradigm for the operations of modern power distribution and transmission systems requires greater grid flexibility that is accompanying an extensive change in the structure of electricity markets, the fruit of the development of the renewable industry and of the growing photovoltaic systems popularized, but in contrast due to the intermittent nature cause variable uncertainties in the power system. Innovative concepts like VPP are becoming a reality, establishing an efficient and effective mechanism. The objectives and components are described in a comprehensive way, and some of the most important are pointed out and presented in detail to contribute with a description of the energy systems and the implicit research needed for sustainability and resilience in the eminent energy scenario with this technology. In addition, the literature and studies of this technology already indicate a direction of this new tool as a promising solution to manage the uncertainties of the renewable energies.
\end{abstract}

Keywords: Virtual Power Plant; Distributed Energy Sources; Smart Grid

\section{Introduction}

With the gradual exhaustion of oil-based energy resources and major concern for the environment, alternatives such as renewable energy generation have been widely implemented in the networks, through government actions, especially in distribution. Two trends are determining the new energy supply: sharp increase in Distributed Generation (DG) and proliferation of renewable electricity generation.

From this, a relatively new concept of power generation and management, draws attention to the growing number of publications in recent years, since Distributed Energy Resources (DER) in the electricity grid strongly depends on their climatic conditions and is a reality that can no longer be forgotten or neglected, due to some types of auxiliary services that they can intervene, such as frequency and voltage regulation in the operation of a distributor. The network operators of the system need to evaluate the intermittent generation during the design and operation of new networks [1].

Coordinating the entire energy system has become a more complex issue with the entry of DERs, since integration is one of the main agents to make significant and significant changes within the energy distribution and transmission systems in a country, to establish an active and intelligent network, and faster service to the growth of demand for a deployment time lower than that of additions to centralized generation requires an active and efficient network that allows decisions to be made on the best way to operate in real time, the same In this way we mention the simultaneous reduction of energy costs and a significant reduction of the environmental impacts of traditional generation. 
Therefore, Virtual Power Plant (VPP) meets this new reality, which is very attractive and needs careful and careful research to facilitate its implementation, where it increases the flexibility and controllability made possible by the embedded generation and the demand for DERs [2]. As a presentation of this concept is still new, many researchers and organizations deal with different definitions of VPPs, which sometimes suppress and sometimes overlap one another, so there is no unified definition respected in the literature. Different authors base their definitions on the physical system structure of a VPP, or on the structure of the control system or also on the purpose of the VPP [3]. However, the convergent definitions show that a VPP is an aggregation of DERs, controllable loads and possible storage devices, besides allowing access to national markets, and to provide energy and auxiliary services [2]. DERs are generally used to displace the power of conventional power plants, but not to displace their capacity, since they are not yet visible to system operators to own an organization and have similar technical and commercial characteristics as a unit generation center [4].

VPP will bridge this barrier by providing visibility and control of system operators and market agents for DERs by providing an appropriate technical and business interface between these system components. Getting better and better use, since a large part is near the centers of consumption and the operators of the system can benefit from the optimized use of all the possible available capacity connected to the network. VPP presents itself as a solution with high reliability and lower cost, using an important tool that is the scheduling of DERs [5] and controllable demand have the opportunity to participate in the real-time operation of transmission and distribution networks, possibly bypass the problem of inherent fluctuation and the intermittence of the DERs where they can deteriorate the stability and safety of the electrical networks. It allows the coherent central control and the coordinated integration of the market of several geographically dispersed electric energy sources in the national territory. At the same time, they share some characteristics similar to microgrid, such as the ability to integrate Demand Response (DR) systems, stores at distribution levels, however, there are some differences that are clarified in this work [2]. And for the implementation of this concept, the issue of Information Technology and Control (ICT) in an advanced measurement infrastructure (AMI) in the distribution network [6] is important.

Evaluating possible aggregations of future and small VPPs in a larger VPP, managing large-scale participation in the wholesale electricity market while simultaneously increasing security of the power system may be a solution, there are results that show the VPP providing such a reserve service, regardless of its role in the energy market [7]. Future networks are expected to accommodate thousands, if not millions, of distributed generators and flexible loads.

The article presents a systematic review that captured interesting insights and that was based on a set of works found in the literature for the different and different definitions of many authors and their components. For the work to have a better reading flow, a technique was used that contains a minimum set of evidence-based items for reports in systematic reviews and meta-analyzes called Preferred Reporting Items for Systematic Reviews and Meta-Analyzes (PRISMA).

\section{Literature Review of the Virtual Power Plant}

This section explores the concept and structures of a VPP, its components, its advantages and disadvantages of the different methods presented by the literature. Its origin is from a structure previously called the Virtual Utility (VU) [8] where it allowed individual participants to provide highly efficient energy services to customers through virtualized sharing of their benefits [9], but over time had its an improved concept with the arrival of VPP, which focuses on the virtual aggregation of DERs and fundamentally has the composition of Distributed Generations (DGs), which may include conventional power plants in addition to intermittent units along with possible flexible loads and energy storage units, not only to be visible in the energy market, but also to be controllable for the system operator and can be competitively profitable in the electricity market. VPP will not be exclusive or unique, since it is necessary to guarantee the safe operation of the energy system, providing support services such as load monitoring, frequency regulation, voltage and reserves, so conventional power plants will be active, but this concept will make the most of DERs [11]. 
Note that there is a noticeable difference between microgrids and VPPs has to be clear in this article, because sometimes they can be confused because they seem the same, but they are not. Micronetworks still face regulatory and policy hurdles while VPPs can, for the most part, be implemented under current regulatory and tariff structures. Another notable difference is that Microgrids may be connected to the electrical system or disconnected, but VPP must always be connected. Storage can be present or not in VPPs but in microgrids they usually require some type of storage [5].

\section{Virtual Power Plant components}

We present the development of a topology for Virtual Power Plant in Figure 1 with establishing connections of information and variable energy resources, together with energy market, based on the expertise acquired through this review. We have investigated that VPP is similar, but not equal, to an Energy Internet (EI), which relies on remote control technology and core optimization [12] of power generation, through the creation of new systems providers and distributed energy sources that can cooperate together in the local area and are controlled by a central control entity. Therefore, improving the competitiveness of DERs in the electricity market becomes possible with applicability where a dual role unit, including producer and consumer, based on the direction of the energy exchanged with the main network, also includes the great potential to reduce the the need for auxiliary services of the existing assets in the distribution and transmission networks. VPPs can have several variations by the derivatives of the sets of different generators and non-renewable and renewable storage devices that may be integrated. Some can play an exclusively commercial role, bringing together the power output of several local units and introducing them to the market as a single entity, while others can perform a more technical operation, being able to adjust the production profile of their generator components or even provide ancillary services to the system.

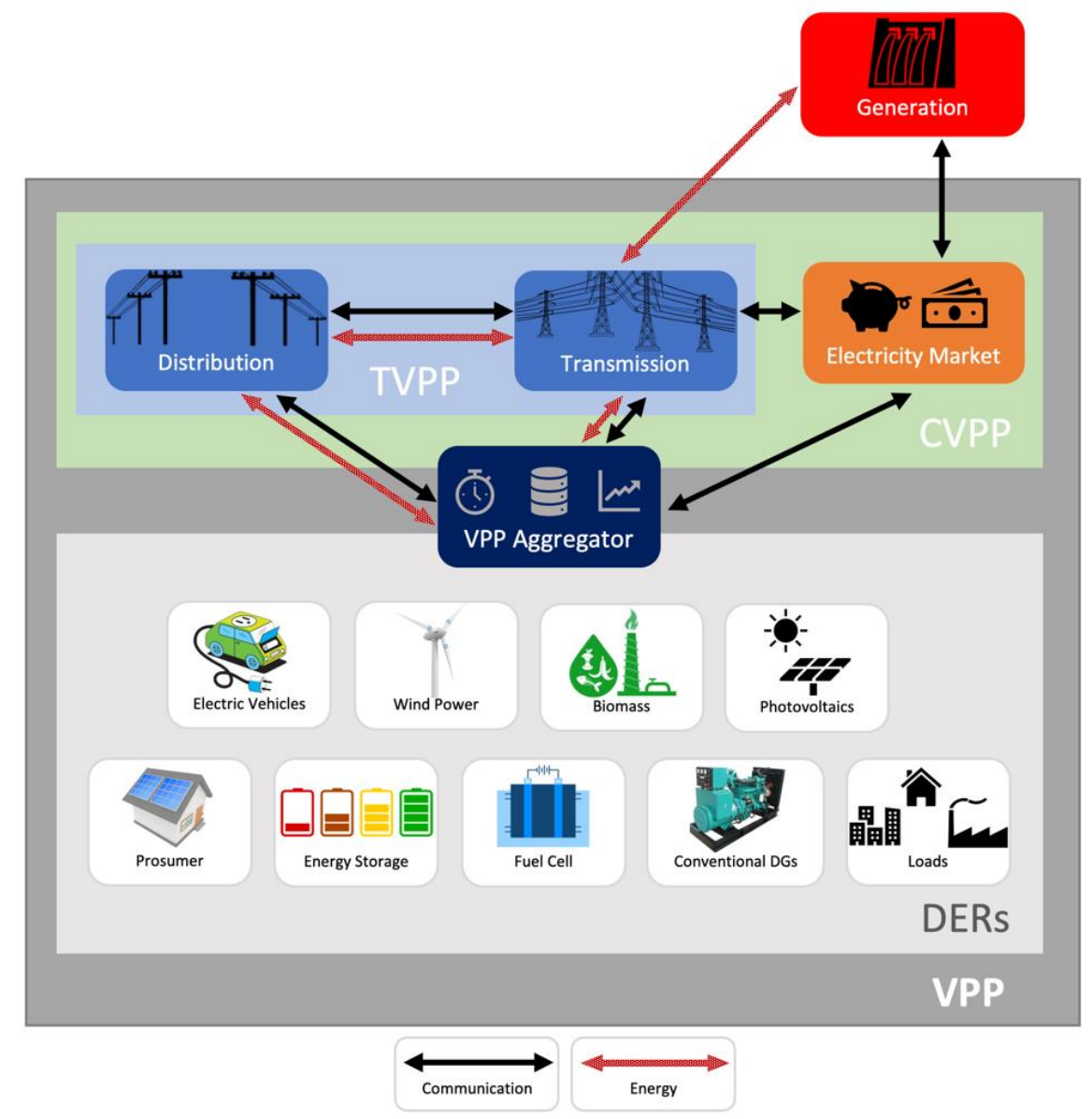

120 Figure 1. The illustration of a proposed topology framework in a Virtual Power Plant 
VPP is able to act directly in the market scenarios through the supply and demand of energy, thus improving system reliability, price fluctuations in the daily or real-time markets, can be used as an additional and effective DR-based mechanism in price to reduce or if necessary until transferring the load, besides following for hours regardless of the stochastic nature of its generation any unforeseeable unavailability. Its main components, commercial and technical [2], together with the others, will be detailed as follows:

\subsection{Technical Virtual Power Plant (TVPP)}

It is an essential component for the existence and functioning of a VPP, it is defined in a comprehensive way in many works, it takes into account the impact of the system on the aggregated profile of the RSD, besides the cost and the operational characteristics of the portfolio, DGs. TVVP works and communicates primarily at the distribution and transmission network level of the same geographic allocation [13], requires detailed knowledge of the local network to provide accurate results to provide the system operator with ancillary and balance services, ensures adequate operations of the DERs real-time management, energy flow management, and some other types of services. It receives and sends real-time information to VPP aggregator, continuously monitors network conditions, statistically analyzes and optimizes DER portfolio planning, and communicates with CVPP about contractual DERs and controllable loads [14]. The importance of TVPP is similar to that of a system operator, especially in the performance of the energy balance [15], usually based on the services required by the VPP operator. It presents visibility in the DERs for the system operator where it owns and collects integrated technical parameters, which contain static technical information and dynamic operations data. After completing its compulsory and contractual dispatch cycle, TVPP recalculates the exact output of each DERs and delivers the liquidated output to the CVPP for calculation and redistribution of profit.

TVPP is involved in managing the system and facilitates the management of local network restrictions, as well as aggregating the DERs to the appropriate local network parameters for presentation at the distribution or transmission level.

\subsection{Commercial Virtual Power Plant (CVPP)}

This component enables the entry of DERs into the energy market as if it were a conventional generator, in direct communication with TVPP it does not have to be limited to an electrical area. Its main and fundamental characteristics are the optimization and programming of aggregated DER units based on the demand of consumers and the expected generation potential of the DR resources [16], besides increasing access to the DGs market and reducing the risk of imbalance for diversity. Trading in the wholesale energy market is one of the main services provided by a CVPP.

The CVPP has profile aggregation and the output that represents the cost and operational characteristics of the DERs portfolio. Provides wholesale energy market negotiation services, negotiation balancing and service delivery to the national system operator (NSO). The CVPP considers the DERs as commercial entities in which they offer the price and quantity of energy they can provide, optimizing the economic use of the VPP portfolio for the electricity market based on anticipated requirements [17]. It presents forecast of production and consumption based on weather forecasting and demand profiles, as well as giving participation of DER units in the energy markets with maximization of the value of the participation of DER units in the energy markets.

TVPP and CVPP decide aspects of VPP and both are subordinate to each other, which means that concerns within the TVPP can force a change in the CVPP and vice versa for the functioning of both. However, the CVPP interacts directly with the energy market. The CVPP is operational in the energy markets and is responsible for passing information on the DER through TVPP.

\subsection{VPP aggregator}

It is an interlocutor between a set of installations and operations of the market that negotiate the aggregations of portfolios of diverse and geographically distributed sources between the networks 
of distribution and transmission, through a provision of profile of production of energy. Its key feature is the reduction of error through knowledge of uncertainties, since for a commercial agent interested in selling energy, this expertise allows accurate forecasts of energy to be negotiated in the stipulated period of trade.

VPP Aggregator communicates directly and in real time with CVPP and TVPP to provide a power production profile. The process includes many details internally, such as algorithms for predicting and programming system components, considering their technical and economic specifications. You can group numbers of small or large generators to generate economies of scale in accessing markets. It is an intermediary between small or large consumers in the VPP system, and may have the storage capacity. It is responsible for balancing the entire system of a VPP as an energy supplier and purchaser of locally generated electricity.

\subsection{Electricity Market}

Currently each country has its own policies and structures in its electricity markets, some allow competitions in the generation and demand sectors to achieve efficiency and freedom of choice for customers, but market architectures are similar across the world. Generally, prices are relatively volatile due to the fact that there is a high mass penetration of a VPP into the system. Their entry into the electricity market would inject third parties with the market share of responsibility, supplying energy in auctions and conducting negotiations, as well as encouraging customers to participate in the electricity market within renewable energy, from consumers to prosumers.

Uncertainties are clearly presented in their economy because of the intermittent and timevarying characteristics that are exposed by the RSDs. The load demand which becomes a common problem in VPP optimization presents a seasonal behavior along with the appearance of electric vehicles, controllable loads. It is well known that the electricity market is in constant transformation since customers have the possibility to change their own use of energy. VPP enters the electricity market while maximizing profitability, flexibility and stability of the system generates significant gains for both stakeholders.

When it comes to the electricity market, operators appear in the following figures called Market Operators whose main function is to improve economic efficiency, system operators where they guarantee the reliability, stability and safety of the interconnected system and the green policies being adopted by many countries in which they increase the use of renewable energy sources.

The most cited and well-known electricity markets in the literature are divided into 4 established models where the first is the Next Day Market [19] presents its separation in central dispatch from the System Operator and has a settlement at a certain time for the next day's operation, Competitive Bidding [20] and Bilateral Negotiation [21], the second model is Real-Time Balancing Market [22] has its transactions during the operational hour, third is Market for ancillary services [23] and the fourth called Common Market [7] which has its early settlement before the transaction.

\subsection{Distributed Energy Resources (DERs)}

They are electricity production or controllable loads that have great potential in the global energy sector and are either directly connected to a local distribution system or connected to an aggregating VPP within the system.

The DERs can include electric vehicles, wind power, biomass and biogas, production photovoltaics, prosumers, energy storage, fuel cell, flexible consumption (controllable / dispatchable loads), small power plants (gas turbines, diesels, etc.), among others.

In particular, in energy storage they adapt the variations of the energy demand to the given level of generation of energy.

\subsection{Communication}

Communication technologies and infrastructures have a bidirectional information system, so VPP not only receives information on the current state of each unit connected to it, but also, if 
necessary, can send control signals to coordinate and control more dispersed power generators in the network, as if they worked as a single plant. The most common term for most researchers is Information Communication Technology (ICT). It is one of the most important requirements for the operation of a VPP [24], usually has all its system is deployed as an autonomous or cloud-based installation. All VPP components such as DERs, CVPP, TVPP and VPP aggregator have this communication infrastructure for the operation of daily operations [25].

The communication of a VPP is not free from cyber-attacks since the whole system is based on hierarchical architecture through protocols and encryptions, this would have serious consequences that affect services provided or functions provided by a VPP. However, there are companies and researchers developing reliable and secure methods to preserve the reliability, performance and safety of a VPP.

\section{Literature Review}

The review of the literature was based on the main and most important articles on the subject in question, the most important journals of the scientific area.

One of the most cited articles on the subject was published in 2017 titled Virtual Power Plant and System Integration of Distributed Energy Resources [2], in which it presents a technical and commercial solution through a case study using a flow algorithm power and characterization of VPP, their main collaboration is to present structure to provide integration of DERs in the energy systems. TVPP and CVPP were presented and demonstrated through this work. A presentation of a concept and architecture of a VPP [26] was presented later and had a main focus and dedication in the optimization of structure and operation.

We present an optimization algorithm to manage a VPP [27], which was based on a direct load control (DLC). Collaborated to reduce the load that the aggregator can present in the electricity market, the model was tested in a real system in the north of Spain to demonstrate its functionality. Similar to this a new power management system of a VPP is proposed in this work its optimal solution is calculated according to a new function, its results are proven through simulations of a realistic scenario [28].

Some important issues such as definition, concepts and their main components of functioning were identified in [29], but different from this review that presents a new component called VPP aggregator in the system.

The authors Mashhour and Moghaddas-Tafreshi write two different articles based on a work with different titles, one presents the formulation of the problem [30] and the other demonstrate their numerical analyzes [7]. The first one explains the bidding problem faced in a VPP and the second one demonstrates that a VPP may have a share in the energy market and can export power to the main network or the energy can be injected into the VPP.

Reliability is a concern at work [31] with the proposal of a new method to evaluate the reliability of active distribution systems with multiple microgrids is demonstrated, based on Monte Carlo simulation.

In the uncertainty generated by alternative sources, a [32] solution was proposed to increase the reliability of these intermittent renewable sources.

A new and improved universal active and reactive power flow controller for three-phase pulse width-modulated voltage source inverters operating at a VPP is presented in the work [33].

A distributed control strategy in a coordinated way so that its generators connected in the network can operate in a VPP in the distribution network [34], was created and tested in a network of distribution of 34 bars of IEEE standard.

In the evaluation on dispatch distributed in VPP systems [35] an optimized dispatch method based on a primal-dual sub-gradient algorithm was presented.

There is a certain tendency of the work to focus on algorithms that optimize the planning [36], an algorithm approach to optimize the thermal and electrical planning of a large-scale VPP (LSVPP) maximizing the daily profit. 
In contrast to other studies [37], this approach to VPP must be interconnected and operate intelligently and this must happen in a way that the time is real, heuristic methods were used to solve the problem.

A method of coordinated control of a VPP is important, coordinated with multiple photovoltaic panels and loads that are controllable, the results were successfully validated through simulations [38].

A decision-tree-based methodology for a VPP, its main contribution was that the applied system can support the network in case of overfrequency [39].

The use of a flexible demand utilization method in the low voltage distribution system takes place in a thermal way, taking advantage of the building thermal mass to defer the energy consumption of electric space heating [40]. Control of this demand is controlled by a VPP.

It presents a solution to avoid the need for a possible forecast of demand or the price of electricity [41]. Its main contribution was to maximize benefits for consumers participating in a PPV.

Many uncertainties exist and the model [42] aborts the load and market price. Using GAMS software for the simulations, its main contribution was to aggregate the DERs in a simulation in order to behave like a VPP and still some strategies of the biddings of the consumers in the energy markets.

A new construction of a two-stage planning for short-term operation in a PPV is proposed [43]. Where the first stage aims to maximize profit and the second stage optimizes the dispatch based on predictive control.

Predictions of loads and uncertainties in power forecasts of a VPP [44] is presented using a LINGO software that adopts intermittent economic dispatching of the simulated power system.

The generation scheduling for a VPP is used [45] taking into account the cost of degradation of the energy storage system. Its main contribution is the use of mixed two-stage linear programming in a VPP to maximize expected profit.

The concept of VPP with integration in the energy market is the main contribution of this work together with the creation of an arbitration strategy for VPPs [46].

An approach over confined programming using fuzzy [47] for the daily scheduling of a VPP, the balance between economy and reliability in operating a VPP for a day in advance was successfully achieved.

Finding a solution to a problem of control and bidding of VPPs that have an impact on consumers and producers that have renewable energy generators and their inelastic demand, this work has the greatest contribution to the development of this strategy that can still supply the capacity of flexible resources thereby avoiding additional capital costs [48].

VPPs face major challenges in view of the varieties of uncertainties faced by distributed generations derived from renewable sources, this problem is solved in part using a two-stage stochastic programming, taking into account the uncertainties as well as markets for revolving reserves and real-time market [49].

A strategy of bidding the next day and once known this strategy was used in real-time scheduling for each hour [50]. VPP in this scenario is a price taker in addition to having a power storage facility participating as a VPP in the markets.

Market-oriented, the price proposal of VPPs are stipulated by the corporation connected in the network. The prices solve the problem through calculations applying information fusion algorithms, and the proof of the methodology was given through a database of energy from the north of China [51].

The main objective of this strategy is to maximize profit. Its main contribution is to associate the variability of risks and uncertainties associated with VPP, which has been incorporated in this case.

A formulation of the requirements for the functionality of a VPP, following the compliments of state-of-the-art techniques for this. A methodology was applied in the communication architecture IEC 61850 and control in a SCADA to prove its functionality [53].

Analysis of multiple VPPs, aiming at unified management through a controller. It took into account factors on the demand side and present and simulate the two dispatch models of a VPP [20]. 
Trends in network asset management and new processes [54], and in the work that the role of the distribution system operator (DSO). One study [55] described a study on the implementation of a PPV.

A centralized VPP dispatch model [16] is introduced to improve the competitiveness of distributed energy resources in the electricity market. Its algorithm presents a topology that considers the uncertainties.

Solution with a scheduling model, where resources can be distributed in a transactional energy structure where risk can be extinguished through this proposal [56].

A stochastic formulation to work with bidding for a micro VPP maximized its profit [57]. The uVPP will provide ancillary services, so end customers will have greater possibilities of choosing their suppliers.

Optimizing bids on the market the next day based on real-time data in a VPP to maximize profit. He used fuzzy optimization in his presented problem [58].

An active distribution market demonstrates effectiveness in the method and its contribution to VPPs, $\mu$ VPPs send price offers, power offers and reserve resources to the operator [59].

Collaborative approach among VPPs [60], where they approach negotiation and cooperation tactics among themselves, their main contribution was to use mixed linear programming to solve the problem. Different from this work, article [61] addresses a strategy of offering a VPP in the real-time and next-day Energy Market, took into account the uncertainty in wind energy production.

In a mathematical way, a model for solving the energy tendering problem of a VPP [62] was presented, given the sources of renewable energies, the uncertainties due to these generations, are also added. The use of the intraday demand response exchange market that improves energy management.

A search algorithm that was tested in a 14-bar IEEE system to control distributed generators and loads in a VPP [63]. Its main contribution to this article was the development of an optimal scheduling controller that controls and coordinates the energy flows in a PPV. In another work the authors [64] developed a real-time algorithm for aggregating energy resources in a VPP, the main contribution was to look for variables in time to solve multi-period optimization problems.

Negotiations between VPPs through regional contracts, where their main focus is the maximization of the opportunities to commercialize energy in the medium term, the main contribution of the work was to prove by means of a case study the proposed model [65].

A formulation [66] through a decision-making tool tending to maximize profit as a goal. Its main contribution was to use non-parametric connections.

Voltage regulation along a line using the VPP model [67] using demand and generation modeling with respective weights.

Decision making for the best strategy for the management of a VPP in a day [68] is made present in this article.

In order to reduce the error [69] that the forecast generates, a static and dynamic aggregation methodology was used.

A mixed integer linear programming model with focus on the planning of the operation considering several factors that allow to evaluate the current options of technological flexibility available in the networks [70].

Solution of two specific problems which has been solved with the development of distributed algorithms [71].

It analyzes the implemented implementations and their challenges, and reports how new technologies directly impact the development of their villages [72].

A case study in Iran shows that the definition is a programming unit containing loads and generations located in an industrial network where they consider the scheduling under normal operating conditions and contingencies [73].

The concepts and applications in the real world [74] of a VPP were addressed, in addition to their challenges. This paper discusses how important it is to apply the VPP concept to manage the system as a whole, thereby lowering costs. 
The investment made in systems with storage can be recovered when used in conjunction with a VPP [75].

Model for solving dispatches for a VPP, optimizing profits and somehow working with variables of uncertainty [76].

Challenges in implementation provides and evaluates a set of policies by different stakeholders. It already clarifies the possibility of different agents such as load aggregators and VPP [77].

A discussion is presented in this paper, showing the points of view of the two structures to identify how important uncertainty, reliability, reactive power, control, emission, stability and demand response are.

The simulation of an IEEE30 bus system considering the proposed method to dribble the influence of the uncertainty generated by the generation sources [79].

A scheduling model that works effectively with regard to the improbabilities that the system of a VVP has and its result provides more regulation capacity for the system [80].

The work with the tool called actor network theory (ANT) where it is a valuable and necessary resource when dealing with digital innovations in the case of VPP [81], taking into account the new communication technologies.

The scenario-based and model-supported analysis has determined the economic performance of a scenario-based VPP by 2030 [82].

Several optimization algorithms to manage the distribution network and as a result we have a functional and effective control strategy where it is clear the importance of the concept of a VPP for the management of electrical energy of the system [83] are discussed in this work.

The article shows how important is the implementation of high-efficiency equipment, together with the use of a PPV aiming at the benefit the power plants and encouraging the participation of users.

VPP is an alternative to overcome the uncertain variables that the renewable energy sources add to the system, the article implements in the problem an imperialist competitive algorithm [85].

The arrival of high technology in the energy industry has brought about, facing some of the reported problems of non-technical losses in addition to tracing a consumer pattern, explain that there are still some points to be studied such as data security and privacy 86 .

There is the importance in the performance of a correct choice of methodology applied in a communication system for a VPP, where low latency and no packet loss is essential in this type of test [87].

In the article Risk-averse formulations and methods for virtual power plant [88], we worked with the comparison of two programming methodologies to see how much more effective the use of a VPP.

Researches employ diversified sources of generation in VPPs in order to reduce the aggregate risk inherent in the intermittency generated by renewable energy, allowing a better return on assets, increasing the expected return [89]. There are several discussions of several new models of the literature on distributed energy systems and their relationships [90]. Some use two scenarios to construct the stochastic programming model [91] in a VPP.

The work the medium-term coalition-forming model of heterogeneous DERs for a commercial virtual power plant [21] applied stochastic programming in the problem of mixed integer programming for decision making in the medium-term energy trade.

Concepts of obtaining profits in the wholesale energy market by a methodology that has lower computational load compared to other methods [92] are presented in this work.

A Two-Stage Increase-Decrease Algorithm To Optimize Distributed Generation In a Virtual Power Plant has taken into account the generation cost involved for developing the algorithm where it has been tested effectively [93].

On maximizing profits under the market model using two-level optimization for the work operation [94] clarifies this point.

The paper Day-ahead resource scheduling of a renewable energy based virtual power plant [95] used a probabilistic model to model the uncertainties in a generic VPP. 
Energetic communities for community energy: A review of key issues and trends shaping integrated community energy systems [96] addresses a modern development to reorganize local energy systems to integrate energy resources.

In the work [12] key concepts like prosumer, microgrid, VPP, smart grid and smart energy are introduced and explored from the perspective of big energy data analysis.

The article Geographic routing protocol for the deployment of virtual power plant within the smart grid [97] effectively demonstrates the use of an ant colony optimization algorithm together for effective delivery of VPP data packets.

A system with hierarchical management structures for the integration of the distribution system with four types of agents [98] is presented.

This work presents [99] an algorithm that considers uncertainties under three objective functions and that uses the response demand to be able to smooth the demand load curve.

Adequate method that encourages members of distributed generations to have an accurate generation forecast by reward for generation and prediction [100] was tested in this paper.

In the work Stochastic operational scheduling of distributed energy resources in a large scale virtual power plant [101] a probabilistic model was used for the planning taking into account the uncertainties in the operation of a VPP.

The article Stochastic profit-based scheduling of industrial virtual power plant using the best demand response strategy [102] presented a new formulation to plan a schedule of VPPs for the following day, successfully obtaining the results of the proposed modeling.

In the article Bi-level optimal dispatch in the Virtual Power Plant considering uncertain agents number [103] a proposal of simulation based on the hierarchical control architecture was presented introducing an algorithm that solves the optimized dispatch of the improbable agents

[104] aims to use stochastic optimization to investigate the optimal bidding strategy for a PPP that uses CHP to compensate for uncertainties regarding RES-based electricity generation and price Marketplace.

Demand Forecasting in the Smart Grid Paradigm: Features and Challenges [105] accuses a key point in the issue of uncertainties that is the prediction of the generations' profiles and demands.

VPPs with wind power, photovoltaic generation and combined heat and power plants, as well as flexible demands were modeled and concluded that self-supply VPPs can achieve very high rates of self-sufficiency in the local load supply, which makes them much less exposed to sudden price changes [106].

The article Review of real-time electricity markets for integrating Distributed Energy Resources and Demand Response [107] provides an analysis of the advances in North America, Australia and Europe, focusing on market architectures and incentive policies for integration.

In the work Risk-based profit allocation to DERs integrated with the virtual power plant using Cooperative Game theory [108] used a new stochastic programming approach using Nucleolus and Shapley value methods such as cooperative approaches to game theory.

The design of a risk-hedging tool for virtual power plants via robust optimization approach [109] provides a technique for exploring an effective decision-making tool for daily and weekly selfplanning of VPPs with the proposed algorithm.

Potential analysis [110] proved to be feasible to have as an additional potential reserve of control as necessary in the use of VPPs to compensate for intermittent generators.

A presentation of an optimization algorithm uses a mixed integer linear programming model in order to improve the capacity of a virtual power plant (VPP) to reduce the error of unbalance of renewable generators [111].

An investigation of control strategies for portfolio aggregation in the energy market and the devices will be manageable by a VPP where it ensures that the services sold by the aggregator to the energy regulator market are effectively delivered [112] is presented in this paper.

An adaptive load dispatching and forecasting strategy for a virtual power plant including renewable energy conversion units [113] presents these sources combined with those of safe energy in a hybrid combination to ensure demand security through a VPP. 
In order to create an active power control strategy for a centralized VPP, the article clarifies this issue [114].

[109] prepares the dispatch of energy equivalent to the possible loss of the largest injection of one of the sources of the VPP to the rest of its sources and with this technique allows the operators of VPP provide strong capacity and effectively participate in the energy market.

A methodology presented that considers the joint dispatch which contemplates the probability of actually using the reservation and distribution network constraints [116].

[15] it is proposed to use IEC / ISO 62264 standards for micrredes and VPPs. In this paper, we propose the use of IEC / ISO 62264 standards for microgrids and VPPs.

A stochastic model for the analysis of the scheduling of operations in VPPs and the uncertainties in the prediction of heat demand are considered via scenarios [117].

[118] presents the development of an algorithm with a two-stage stochastic integer linear programming to have the maximum expected profit of a VPP operator.

Some possible configurations of VPP that could be created on the island [119] since it is a very suitable place for simulation and exploration of new technologies for power generation and energy storage.

An energy management model for a VPP is analyzed through a case study for the state of California with real data [120].

The uncertainties in prices and generation sources for a bid with greater optimization of a VPP in the electricity market of the following day is discussed try application in a system of 18 buses.

In article [122] VPP is cited when the fuel cell operates independently of the heating demand profile of the household. Instead, the control strategy takes into account only the electricity prices and, regardless of the need to heat the home, determines whether the fuel cell should work or not.

A linear schedule of stochastic mixed integer two-stage integers that maximizes the expected profit from VPP and considers that most of the trading takes place in the next day market [123] has been tabled.

The paper titled Virtual power plant mid-term dispatch optimization [124] shows a model with VPP operation planning with the proposal of a stochastic stock-based conservative offer strategy.

In article [125] it works with a hypothetical scenario that operated together with a VPP indicate that the reduction of wind variability was achieved.

VPP was inserted to support a strategy in the rational use of these and other supply systems

Exploring the Value of Flexibility: The Smart Grid Discussion [127] presents two distinct distinct operating strategies for a VPP.

The relevance of the correct sizing of energy storage capacity within a VPP structure in order to have the highest gain and optimization [128] is very important according to the authors.

The developments that occurred in a project where he developed mathematical formulations solved by non-linear programming techniques [129] were presented.

[130] exhibits a solution using standards-based power system communication and algorithms for VPP control with enhanced optimization.

In the article Decentralised optimization of cogeneration in virtual power plants [131] an optimization methodology was implemented with algorithm based on mixed integer linear programming.

In the work Improved Heat Demand Prediction of Individual Households [132] VPP is cited as an option to maximize the energy efficiency of the current power grid.

A review of the auction structures that receive VPPs began in 2001 [133] and it was observed that the aspects differ between the various auctions.

In article [134] the main objective is to reduce the cost of operating a VPP with the same quality of system energy.

Recently an article [135] has appeared that presents an internal and external perspective of the system where it interprets its participation in the market of electricity and clarifies the concept of how the role of a VPP will play in the future of the energy system. 
[136] applied this protocol and verifying the quality of the service taking into account several parameters such as security, latency, loss of packets among others in the public infrastructure of the Internet.

Uncertainties of virtual power plant: Problems and countermeasures [137] developed an optimal algorithm that addresses 3 of the main uncertainty factors of a VPP.

The [138] aims to model the commercialization of electricity between a VPP and its participants.

In [139] he presents in his work that $59 \%$ of the works in VPPs are simulations and that only $2 \%$ are real projects implemented, one notices how new this technology is and that the great majority of the works are focused on simulation or small prototypes.

Understanding how much each unit of electricity produced by each type of technology can change the price of electricity for the development of strategies [140] are challenges described in that article.

Presentation of wind power, solar energy and energy storage modes with model and the typical scenarios of operation of a VPP [141].

[142] developed and presented an algorithm that divides the decision area of a VPP, with reduction of variables. In the article The Virtual Power Plant Architecture for the Demand-Side Management of Smart Prosumers [143] a general mixed linear linear programming (MILP) model was applied.

A decentralized two-stage stochastic dispatch model [144] is proposed based on the synchronous alternate direction multiplier method for a distribution system with multiple VPPs.

In a Multiple Objective Compromised Method for Power Management in Virtual Power Plants [145] it presents an optimization model of VPP operations through a multi-objective optimization algorithm.

An integer mixed nonlinear programming with intertemporal constraints with optimal dispatch strategy to obtain the expected maximum profit under some floating parameters [146] is developed for a PPV.

In the article The Optimal Dispatch of the Power System Containing Virtual Power Plants under Fog and Haze Weather [147] a model was used to predict the production and the photovoltaic load taking into account the climate.

A framework for managing different types of resources relevant to power management for VPP, given the great complexity and variety of resources and the need for collaboration between systems in different domains [148] is worked out in this article.

The application of a model with the advantages of lower communication costs and greater robustness of the system was applied [149]. Another contribution through discussion of VPP when explaining about the facilitators of the system, which include ICT and SG is presented by the authors [150].

The work Aggregation Potentials for Buildings - Business Models of Demand Response and Virtual Power Plants [151] presents the development of some negotiation models for market share of electricity.

In the two-stage Coordinated Operational Strategy for Distributed Energy Resources, Considering Wind Power Curtailment Penalty Cost [152] presents an optimal scheduling model for PPV participating in markets and with risk aversion and levels of uncertainty and with it effectively assisting in integration by reducing the cost of risk aversion.

In A Remedial Strategic Scheduling Model for Load Serving Entities Considering the Interaction between Grid-Level Energy Storage and Virtual Power Plants [153] has developed a strategic schedule for daily profit based on a two-level optimization model.

The work presented a proposed model that aims to maximize the profitability of the project, and to develop a new model for the use of renewable energy. operational risk.

A simulation methodology with the potential of this system to provide aggregate storage when combined in a VPP [155] with electric vehicles.

There are basic components of a VPP that are presented in the work [156] as the uncertainties of photovoltaic generation, wind and demand side response. 
A key point of discussion and a viable reference to investors' ideal perspective through calculations using portfolio theory [157] has a discussion and the uncertainties that are the main factors affecting the system of a PPV when reduced, its capacity correspondingly.

Briefly, its concepts are presented, then probability models are introduced to address the uncertainties and, finally, demand-side load modeling [3], using mixed-line linear programming. The optimal dispatch problem of a VPP was solved in this way. proposal.

Recently I was published in a congress a work that proposes a strategy of control by means of algorithm applied in a TVPP, consisted in tests in feeders of nodes of the IEEE 73 buses [158].

Another paper that drew attention in 2019 is an article that investigates residential power management with photovoltaic roofing systems as a virtual scale small-scale power plant (SSVPP) connected to the main grid [159].

Power planning and regulation of a PPV are discussed together with their uncertainties [160] with the use of demand response programs, a regulation payment mechanism based on the participation of regulatory capacity is presented.

When it comes to energy management and operation of a VPP article [161] presents a system based on the imperialist competitive algorithm for optimal energy management. Another work presents a model for the planning of a VPP [162] by scheduling systems schedules and consisting of several energy centers was presented and obtained an optimal operation in the energy networks simultaneously.

A relevant discussion that brings up the issue of electric vehicles in a PPV [163], how users could have an appropriate mixed trading strategy where they use their storage capacity for system-wide arbitrage operations and car sharing scenarios.

\subsection{Advantages of VPPS}

Use of DERs to provide services to the distribution and transmission network;

Losses will be reduced;

Failures will be identified through a management system;

Auxiliary in system voltage and frequency regulation

Prossumers will have economic benefits;

Higher visibility of DER units for consideration in network operation;

Large-scale economic integration of renewable energies while maintaining system security;

Open energy markets for small-scale participants;

Increase the overall efficiency of electric power;

New business opportunities.

\subsection{Disadvantages of VPPS}

Intertemporal dependence of generation resources;

Regulatory frameworks should be created to promote the contribution of VPPS to the energy system;

With the implementation of VPP some sensitive devices may present some flaws, which is the case of network protection systems due to some type of instability in the DERs, research will have to be intensified in this area;

Possibility of hakers attacks;

Possibility of loss of synchronism of the DER unit.

\section{Conclusion}

This paper presented a review on Virtual Power Plant where it covered almost all articles of the topic within the literature. Therefore, it can be said that in almost all simulation models of VPPs, the sharing and gathering of information form the basis of the operation and optimization of VPP.

The world still has as main source the large power plants that provide energy systems. But this situation will change due to the number of DER units increasing and the VPP having in its scope the 
625

626

627

628

629

630

631

632

633

634

635

636

637

638

639

640

641

642

643

644

645

646

647

648

649

650

651

geographic distribution, its integration by the VPP will have presence with a dynamic profile providing the control under the quality of generation of these resources. Its implementation could postpone new investments in transmission and distribution lines, also allowing the possibility of access and visibility in all energy markets, benefiting to optimize its position and maximize revenue opportunities, thus giving rise to economic interest in the implementation.

Each VPP system in each revised article differs in detail. There are many authors and approaches to the concept of PPV. But the central essence perseveres the same. It is concluded that the present revision can help in the development of future research in this field to open new windows for future and important investigations.

The perspective on the VPPS are the most optimistic, since it is a concept that has consistency thus becoming a viable and interesting option to integrate the DERs and prosumers in the electric energy system. System operation can benefit from the optimized use of all available capacity in the world through the use of VPPS.

Author Contributions: Investigation, methodology L.F.R. writing-draft preparation, L.F.R. and L.N.C.; writing - review and editing, L.F.R. and L.N.C.; overall supervision, L.N.C.

Funding: Please add: "This research received no external funding" or "This research was funded by NAME OF FUNDER, grant number XXX" and "The APC was funded by XXX". Check carefully that the details given are accurate and use the standard spelling of funding agency names at https://search.crossref.org/funding, any errors may affect your future funding.

Acknowledgments: The authors would like to thank the Federal University of Rondônia and support from Federal University of Santa Maria, Santa Maria - RS, Brazil, funding from CNPq PQ 1-D 310761/2018-2, CNPq process 465640/2014-1, CAPES process no. 23038.000776/2017-54 and FAPERGS 17/2551-0000517-1, support from CNPq, Brazilian National Council for Scientific and Technological Development - Brazil. This study was also financed in part by the Coordenação de Aperfeiçoamento de Pessoal de Nível Superior - Brasil (CAPES/PROEX) - Finance Code 001.

Conflicts of Interest: The authors declare no conflict of interest.

\section{Nomenclature:}

AMI advanced metering infrastructure

ANT actor network theory

CHP combined heat-and-power

CVPP Commercial Virtual Power Plant

DG Distributed Generation

DLC direct load control

DR Demand Response

DSO distribution system operator

EI Energy Internet

GAMS General Algebraic Modeling System

GD Gerações Distribuída

ICT Information Technology and Control

LSVPP large-scale VPP

MILP mixed linear linear programming

NSO national system operator

SG Smart Grid

SSVPP small-scale power plant

TVPP Technical Virtual Power Plant

VPP Virtual Power Plant

VU Virtual Utility 


\section{References}

1. El Bakari, K.; Kling, W.L. Virtual power plants: An answer to increasing distributed generation. IEEE PES Innov. Smart Grid Technol. Conf. Eur. ISGT Eur. 2010, 1-6.

2. Pudjianto, D.; Pudjianto, D.; Ramsay, C.; Ramsay, C.; Strbac, G.; Strbac, G. Virtual power plant and system integration of distributed energy resources. Renew. Power Gener. IET 2007, 1, 10-16.

3. Liu, Z.; Zheng, W.; Qi, F.; Wang, L.; Zou, B.; Wen, F.; Xue, Y. Optimal dispatch of a virtual power plant considering demand response and carbon trading. Energies 2018, 11, 121693718.

4. Ekanayake, J.; Liyanage, K.; Wu, J.; Yokoyama, A.; Jenkins, N. Smart Grid: Technology and Applications; 2012; ISBN 9780470974094.

5. Mancarella, P. MES (multi-energy systems): An overview of concepts and evaluation models. Energy 2014, $65,1-17$.

6. de Carvalho, R.S.; Sen, P.K.; Velaga, Y.N.; Ramos, L.F.; Canha, L.N. Communication system design for an advanced metering infrastructure. Sensors (Switzerland) 2018, 18, 1-11.

7. Mashhour, E.; Moghaddas-Tafreshi, S.M. Bidding Strategy of Virtual Power Plant for Participating in Energy and Spinning Reserve Markets\&\#x2014;Part II: Numerical Analysis. IEEE Trans. Power Syst. 2011, 26, 957-964.

8. Bayegan, M. A vision of the future grid. IEEE Power Eng. Rev. 2001, 21, 10-12.

9. Awerbuch, S.; Preston, A. The Virtual Utility: Accounting, Technology \& Competitive Aspects of the Emerging Industry; 2012; ISBN 1461561671.

10. Bourdette, R. An Economical \& Technical Study of the Participation of a Virtual Power Plant on the Swiss Balancing Market: WRITTEN IN COLLABORATION WITH .... 2016.

11. Nahmias, S. International Series in Operations Research \& Management Science; 2011; Vol. 226; ISBN 9781441979988.

12. Zhou, K.; Yang, S.; Shao, Z. Energy Internet: The business perspective. Appl. Energy 2016, 178, $212-222$.

13. Kolenc, M.; Ihle, N.; Gutschi, C.; Nemček, P.; Breitkreuz, T.; Gödderz, K.; Suljanović, N.; Zajc, M. Virtual power plant architecture using OpenADR 2.0b for dynamic charging of automated guided vehicles. Int. J. Electr. Power Energy Syst. 2019, 104, 370-382.

14. Bakari, K. El; Kling, W.L. Integration of Distributed Energy Resources with Virtual Power Plants Technical, Regulatory and Socio-economic Considerations. Int. J. Energy Power 2014, 3, 35-41.

15. Palizban, O.; Kauhaniemi, K.; Guerrero, J.M. Microgrids in active network management - Part I: Hierarchical control, energy storage, virtual power plants, and market participation. Renew. Sustain. Energy Rev. 2014, 36, 428-439.

16. Zhang, G.; Jiang, C.; Wang, X.; Li, B.; Zhu, H. Bidding strategy analysis of virtual power plant considering demand response and uncertainty of renewable energy. IET Gener. Transm. Distrib. 2017, 11, 3268-3277.

17. Tarazona, C.; Muscholl, M.; Lopez, R.; Passelergue, J.C. Integration of distributed energy resources in the operation of energy management systems. 1st IEEE-PES/IAS Conf. Sustain. Altern. Energy, SAE 2009 - Proc. 2009, 1-5.

18. Lukovic, S.; Kaitovic, I.; Mura, M.; Bondi, U. Virtual power plant as a bridge between distributed energy resources and smart grid BT - 43rd Annual Hawaii International Conference on System Sciences, HICSS43, January 5, 2010 - January 8, 2010. 2010, “University of Hawai'i”; Shidler College of Busine.

19. Yuan, W.; Zhai, Q. Power-based transmission constrained unit commitment formulation with energybased reserve. IET Gener. Transm. Distrib. 2016, 11, 409-418.

20. Wang, Y.; Ai, X.; Tan, Z.; Yan, L.; Liu, S. Interactive dispatch modes and bidding strategy of multiple virtual power plants based on demand response and game theory. IEEE Trans. Smart Grid 2016, 7, 510-519.

21. Shabanzadeh, M.; Sheikh-El-Eslami, M.K.; Haghifam, M.R. A medium-term coalition-forming model of heterogeneous DERs for a commercial virtual power plant. Appl. Energy 2016, 169, 663-681.

22. Jiayi, H.; Chuanwen, J.; Rong, X. A review on distributed energy resources and MicroGrid. Renew. Sustain. Energy Rev. 2008, 12, 2472-2483.

23. Raineri, R.; Ríos, S.; Schiele, D. Technical and economic aspects of ancillary services markets in the electric power industry: an international comparison. Energy Policy 2006, 34, 1540-1555.

24. Kazičková, T.; Buhnova, B. ICT architecture for the Smart Grid: Concept overview. 2016 Smart Cities Symp. Prague, SCSP 2016 2016, 16-19.

25. Panajotovic, B.; Jankovic, M.; Odadzic, B. ICT and smart grid. 2011 10th Int. Conf. Telecommun. Mod. Satell. Cable Broadcast. Serv. TELSIKS 2011 - Proc. Pap. 2011, 118-121. 
26. Lombardi, P.; Powalko, M.; Rudion, K. Optimal operation of a virtual power plant. IEEE Power Energy Soc. Gen. Meet. 2009, 1-6.

27. Ruiz, N.; Cobelo, I.; Oyarzabal, J. A Direct Load Control Model for Virtual Power Plant Management. IEEE Trans. Power Syst. 2009, 24, 959-966.

28. Aloini, D.; Crisostomi, E.; Raugi, M.; Rizzo, R. Optimal power scheduling in a Virtual Power Plant. Int. Conf. Exhib. Innov. Smart Grid Technol. 2011, 1-7.

29. Saboori, H.; Mohammadi, M.; Taghe, R. Virtual power plant (VPP), definition, concept, components and types. Asia-Pacific Power Energy Eng. Conf. APPEEC 2011.

30. Mashhour, E.; Moghaddas-Tafreshi, S.M. Bidding Strategy of Virtual Power Plant for Participating in Energy and Spinning Reserve Markets-Part I: Problem Formulation. IEEE Trans. Power Syst. 2011, 26, 949-956.

31. Bie, Z.; Zhang, P.; Li, G.; Hua, B.; Meehan, M.; Wang, X. Reliability evaluation of active distribution systems including microgrids. IEEE Trans. Power Syst. 2012, 27, 2342-2350.

32. Vasirani, M.; Kota, R.; Cavalcante, R.L.G.; Ossowski, S.; Jennings, N.R. An agent-based approach to virtual power plants of wind power generators and electric vehicles. IEEE Trans. Smart Grid 2013, 4, 1314-1322.

33. Sreeram, V.; Dasouki, S.; Mishra, Y.; Khan, H.; Iu, H.H.C. Universal active and reactive power control of electronically interfaced distributed generation sources in virtual power plants operating in grid-connected and islanding modes. IET Gener. Transm. Distrib. 2013, 7, 885-897.

34. Gan, D.; Dai, C.; Li, H.; Xin, H.; Li, N. Virtual power plant-based distributed control strategy for multiple distributed generators. IET Control Theory Appl. 2013, 7, 90-98.

35. Yang, H.; Yi, D.; Zhao, J.; Dong, Z. Distributed optimal dispatch of virtual power plant via limited communication. IEEE Trans. Power Syst. 2013, 28, 3511-3512.

36. Giuntoli, M.; Poli, D. Optimized thermal and electrical scheduling of a large scale virtual power plant in the presence of energy storages. IEEE Trans. Smart Grid 2013, 4, 942-955.

37. Petersen, M.K.; Hansen, L.H.; Bendtsen, J.; Edlund, K.; Stoustrup, J. Heuristic Optimization for the Discrete Virtual Power Plant Dispatch Problem. 2014, 5, 2910-2918.

38. Xin, H.; Gan, D.; Liu, Y.; Wang, Z. Control of virtual power plant in microgrids: a coordinated approach based on photovoltaic systems and controllable loads. IET Gener. Transm. Distrib. 2015, 9, 921-928.

39. Moutis, P.; Hatziargyriou, N.D. Decision trees-aided active power reduction of a virtual power plant for power system over-frequency mitigation. IEEE Trans. Ind. Informatics 2015, 11, 251-261.

40. Thavlov, A.; Bindner, H.W. Utilization of flexible demand in a virtual power plant set-up. IEEE Trans. Smart Grid 2015, 6, 640-647.

41. Mnatsakanyan, A.; Kennedy, S.W. A novel demand response model with an application for a virtual power plant. IEEE Trans. Smart Grid 2015, 6, 230-237.

42. Hosseinian, S.H.; Karimyan, P.; Khatami, R.; Abedi, M. Stochastic approach to represent distributed energy resources in the form of a virtual power plant in energy and reserve markets. IET Gener. Transm. Distrib. 2016, 10, 1792-1804.

43. Yang, J.; Dong, Z.Y.; Meng, K.; Wong, K.P.; Luo, F.; Qiu, J. Short-term operational planning framework for virtual power plants with high renewable penetrations. IET Renew. Power Gener. 2016, 10, 623-633.

44. Huang, C.; Yue, D.; Xie, J.; Li, Y.; Wang, K. Economic dispatch of power systems with virtual power plant based interval optimization methodddrfegtregrertq. CSEE J. Power Energy Syst. 2016, 2, 74-80.

45. Cao, Y.; Li, C.; Liu, X.; Zhou, B.; Chung, C.Y.; Chan, K.W. Optimal scheduling of virtual power plant with battery degradation cost. IET Gener. Transm. Distrib. 2016, 10, 712-725.

46. Nezamabadi, H.; Setayesh Nazar, M. Arbitrage strategy of virtual power plants in energy, spinning reserve and reactive power markets. IET Gener. Transm. Distrib. 2016, 10, 750-763.

47. Piao, L.; Fan, S.; Ai, Q. Fuzzy day-ahead scheduling of virtual power plant with optimal confidence level. IET Gener. Transm. Distrib. 2016, 10, 205-212.

48. Zhao, Q.; Shen, Y.; Li, M. Control and Bidding Strategy for Virtual Power Plants with Renewable Generation and Inelastic Demand in Electricity Markets. IEEE Trans. Sustain. Energy 2016, 7, 562-575.

49. Dabbagh, S.R.; Sheikh-El-Eslami, M.K. Risk Assessment of Virtual Power Plants Offering in Energy and Reserve Markets. IEEE Trans. Power Syst. 2016, 31, 3572-3582.

50. Rahimiyan, M.; Baringo, L. Strategic Bidding for a Virtual Power Plant in the Day-Ahead and Real-Time Markets: A Price-Taker Robust Optimization Approach. IEEE Trans. Power Syst. 2016, 31, 2676-2687. 
51. Xu, Z.Y.; Qu, H.N.; Shao, W.H.; Xu, W.S. Virtual Power Plant-Based Pricing Control for Wind/Thermal Cooperated Generation in China. IEEE Trans. Syst. Man, Cybern. Syst. 2016, 46, 706-712.

52. Kardakos, E.G.; Simoglou, C.K.; Bakirtzis, A.G. Optimal Offering Strategy of a Virtual Power Plant: A Stochastic Bi-Level Approach. IEEE Trans. Smart Grid 2016, 7, 794-806.

53. Etherden, N.; Vyatkin, V.; Bollen, M. Virtual Power Plant for Grid Services using IEC 61850. IEEE Trans. Ind. Informatics 2016, 12, 1-1.

54. Thomas, D.; Iain, M.; Dale, G. Virtual power plants leveraging energy flexibility in regional markets. CIRED - Open Access Proc. J. 2017, 2017, 2939-2943.

55. Pudjianto, D.; Strbac, G.; Boyer, D. Virtual power plant: Managing synergies and conflicts between transmission system operator and distribution system operator control objectives. CIRED - Open Access Proc. J. 2017, 2017, 2049-2052.

56. Qiu, J.; Meng, K.; Zheng, Y.; Dong, Z.Y. Optimal scheduling of distributed energy resources as a virtual power plant in a transactive energy framework. IET Gener. Transm. Distrib. 2017, 11, 3417-3427.

57. Fu, H.; Wu, Z.; Zhang, X.-P.; Brandt, J. Contributing to DSO's Energy-Reserve Pool: A Chance-Constrained Two-Stage $\mu$ VPP Bidding Strategy. IEEE Power Energy Technol. Syst. J. 2017, 4, 1-1.

58. Al-Awami, A.T.; Amleh, N.; Muqbel, A. Optimal Demand Response Bidding and Pricing Mechanism with Fuzzy Optimization: Application for a Virtual Power Plant. IEEE Trans. Ind. Appl. 2017, 53, 1-1.

59. Fu, H.; Zhang, X.P. Market Equilibrium in Active Distribution System with $\mu$ VPPs: A Coevolutionary Approach. IEEE Access 2017, 5, 8194-8204.

60. Shabanzadeh, M.; Sheikh-El-Eslami, M.-K.; Haghifam, M.-R. Risk-based medium-term trading strategy for a virtual power plant with first-order stochastic dominance constraints. IET Gener. Transm. Distrib. 2017, 11, 520-529.

61. Baringo, L.; Baringo, A. A Stochastic Adaptive Robust Optimization Approach for the Generation and Transmission Expansion Planning. IEEE Trans. Power Syst. 2017, 32, 1-1.

62. Nguyen, H.T.; Le, L.B.; Wang, Z. A Bidding Strategy for Virtual Power Plants With Intraday Demand Response Exchange Market Using Stochastic Programming. IEEE Trans. Ind. Appl. 2018, 54, 3044-3055.

63. Abdolrasol, M.G.M.; Hannan, M.A.; Member, S.; Mohamed, A.; Member, S.; Abidin, I.Z.; Member, S.; Uddin, M.N.; Member, S. An Optimal Scheduling Controller for Virtual Power Plant and Microgrid Integration using Binary Backtracking Search Algorithm. 2017, 9994, 1-8.

64. Anese, E.D.; Guggilam, S.S.; Simonetto, A.; Chen, Y.C.; Dhople, S. V. Optimal Regulation of Virtual Power Plants. IEEE Trans. Power Syst. 2018, 33, 1868-1881.

65. Shabanzadeh, M.; Sheikh-El-Eslami, M.K.; Haghifam, M.R. An interactive cooperation model for neighboring virtual power plants. Appl. Energy 2017, 200, 273-289.

66. Toubeau, J.F.; De Grève, Z.; Vallée, F. Medium-Term Multimarket Optimization for Virtual Power Plants: A Stochastic-Based Decision Environment. IEEE Trans. Power Syst. 2018, 33, 1399-1410.

67. Moutis, P.; Georgilakis, P.S.; Hatziargyriou, N.D. Voltage Regulation Support Along a Distribution Line by a Virtual Power Plant Based on a Center of Mass Load Modeling. IEEE Trans. Smart Grid 2016, 9, 1-1.

68. Javad Kasaei, M.; Gandomkar, M.; Nikoukar, J. Optimal Operational Scheduling of Renewable Energy Sources Using Teaching-Learning Based Optimization Algorithm by Virtual Power Plant. J. Energy Resour. Technol. 2017, 139, 062003.

69. Wei, C.; Xu, J.; Liao, S.; Sun, Y.; Jiang, Y.; Ke, D.; Zhang, Z.; Wang, J. A bi-level scheduling model for virtual power plants with aggregated thermostatically controlled loads and renewable energy. Appl. Energy 2018, 224, 659-670.

70. Alemany, J.M.; Arendarski, B.; Lombardi, P.; Komarnicki, P. Accentuating the renewable energy exploitation: Evaluation of flexibility options. Int. J. Electr. Power Energy Syst. 2018, 102, 131-151.

71. Chen, G.; Li, J. A fully distributed ADMM-based dispatch approach for virtual power plant problems. Appl. Math. Model. 2018, 58, 300-312.

72. V., S.K.; Prasad, J.; Samikannu, R. Barriers to implementation of smart grids and virtual power plant in subsaharan region-focus Botswana. Energy Reports 2018, 4, 119-128.

73. Hooshmand, R.A.; Nosratabadi, S.M.; Gholipour, E. Event-based scheduling of industrial technical virtual power plant considering wind and market prices stochastic behaviors - A case study in Iran. J. Clean. Prod. 2018, 172, 1748-1764.

74. Hirsch, A.; Parag, Y.; Guerrero, J. Microgrids: A review of technologies, key drivers, and outstanding issues. Renew. Sustain. Energy Rev. 2018, 90, 402-411. 
75. Heredia, F.J.; Cuadrado, M.D.; Corchero, C. On optimal participation in the electricity markets of wind power plants with battery energy storage systems. Comput. Oper. Res. 2018, 96, 316-329.

76. Liu, Y.; Li, M.; Lian, H.; Tang, X.; Liu, C.; Jiang, C. Optimal dispatch of virtual power plant using interval and deterministic combined optimization. Int. J. Electr. Power Energy Syst. 2018, 102, 235-244.

77. de A. Dantas, G.; de Castro, N.J.; Dias, L.; Antunes, C.H.; Vardiero, P.; Brandão, R.; Rosental, R.; Zamboni, L. Public policies for smart grids in Brazil. Renew. Sustain. Energy Rev. 2018, 92, 501-512.

78. Nosratabadi, S.M.; Hooshmand, R.A.; Gholipour, E. A comprehensive review on microgrid and virtual power plant concepts employed for distributed energy resources scheduling in power systems. Renew. Sustain. Energy Rev. 2017, 67, 341-363.

79. Tan, Z.; Wang, G.; Ju, L.; Tan, Q.; Yang, W. Application of CVaR risk aversion approach in the dynamical scheduling optimization model for virtual power plant connected with wind-photovoltaic-energy storage system with uncertainties and demand response. Energy 2017, 124, 198-213.

80. Shayegan-Rad, A.; Badri, A.; Zangeneh, A. Day-ahead scheduling of virtual power plant in joint energy and regulation reserve markets under uncertainties. Energy 2017, 121, 114-125.

81. Kolloch, M.; Dellermann, D. Digital innovation in the energy industry: The impact of controversies on the evolution of innovation ecosystems. Technol. Forecast. Soc. Change 2018, 136, 254-264.

82. Loßner, M.; Böttger, D.; Bruckner, T. Economic assessment of virtual power plants in the German energy market - A scenario-based and model-supported analysis. Energy Econ. 2017, 62, 125-138.

83. Othman, M.M.; Hegazy, Y.G.; Abdelaziz, A.Y. Electrical energy management in unbalanced distribution networks using virtual power plant concept. Electr. Power Syst. Res. 2017, 145, 157-165.

84. Li, Y.; Gao, W.; Ruan, Y. Feasibility of virtual power plants (VPPs) and its efficiency assessment through benefiting both the supply and demand sides in Chongming country, China. Sustain. Cities Soc. 2017, 35, 544-551.

85. Kasaei, M.J.; Gandomkar, M.; Nikoukar, J. Optimal management of renewable energy sources by virtual power plant. Renew. Energy 2017, 114, 1180-1188.

86. Kumar V., S.; Prasad, J.; Samikannu, R. Overview, issues and prevention of energy theft in smart grids and virtual power plants in Indian context. Energy Policy 2017, 110, 365-374.

87. Kolenc, M.; Nemček, P.; Gutschi, C.; Suljanović, N.; Zajc, M. Performance evaluation of a virtual power plant communication system providing ancillary services. Electr. Power Syst. Res. 2017, 149, 46-54.

88. Lima, R.M.; Conejo, A.J.; Langodan, S.; Hoteit, I.; Knio, O.M. Risk-averse formulations and methods for a virtual power plant. Comput. Oper. Res. 2018, 96, 350-373.

89. Gersema, G.; Wozabal, D. Risk-optimized pooling of intermittent renewable energy sources. J. Bank. Financ. 2016, 0, 1-14.

90. Howell, S.; Rezgui, Y.; Hippolyte, J.L.; Jayan, B.; Li, H. Towards the next generation of smart grids: Semantic and holonic multi-agent management of distributed energy resources. Renew. Sustain. Energy Rev. 2017, 77, 193-214.

91. Ju, L.; Tan, Z.; Yuan, J.; Tan, Q.; Li, H.; Dong, F. A bi-level stochastic scheduling optimization model for a virtual power plant connected to a wind-photovoltaic-energy storage system considering the uncertainty and demand response. Appl. Energy 2016, 171, 184-199.

92. Rahmani-Dabbagh, S.; Sheikh-El-Eslami, M.K. A profit sharing scheme for distributed energy resources integrated into a virtual power plant. Appl. Energy 2016, 184, 313-328.

93. Kumar, K.P.; Saravanan, B.; Swarup, K.S. A Two Stage Increase-decrease Algorithm to Optimize Distributed Generation in a Virtual Power Plant. Energy Procedia 2015, 90, 276-282.

94. Cui, H.; Li, F.; Hu, Q.; Bai, L.; Fang, X. Day-ahead coordinated operation of utility-scale electricity and natural gas networks considering demand response based virtual power plants. Appl. Energy 2016, 176, 183-195.

95. Zamani, A.G.; Zakariazadeh, A.; Jadid, S. Day-ahead resource scheduling of a renewable energy based virtual power plant. Appl. Energy 2016, 169, 324-340.

96. Koirala, B.P.; Koliou, E.; Friege, J.; Hakvoort, R.A.; Herder, P.M. Energetic communities for community energy: A review of key issues and trends shaping integrated community energy systems. Renew. Sustain. Energy Rev. 2016, 56, 722-744.

97. Rekik, M.; Chtourou, Z.; Mitton, N.; Atieh, A. Geographic routing protocol for the deployment of virtual power plant within the smart grid. Sustain. Cities Soc. 2016, 25, 39-48. 
98. Hu, J.; Morais, H.; Lind, M.; Bindner, H.W. Multi-agent based modeling for electric vehicle integration in a distribution network operation. Electr. Power Syst. Res. 2016, 136, 341-351.

99. Ju, L.; Li, H.; Zhao, J.; Chen, K.; Tan, Q.; Tan, Z. Multi-objective stochastic scheduling optimization model for connecting a virtual power plant to wind-photovoltaic-electric vehicles considering uncertainties and demand response. Energy Convers. Manag. 2016, 128, 160-177.

100. Robu, V.; Chalkiadakis, G.; Kota, R.; Rogers, A.; Jennings, N.R. Rewarding cooperative virtual power plant formation using scoring rules. Energy 2016, 117, 19-28.

101. Zamani, A.G.; Zakariazadeh, A.; Jadid, S.; Kazemi, A. Stochastic operational scheduling of distributed energy resources in a large scale virtual power plant. Int. J. Electr. Power Energy Syst. 2016, 82, 608-620.

102. Nosratabadi, S.M.; Hooshmand, R.A.; Gholipour, E. Stochastic profit-based scheduling of industrial virtual power plant using the best demand response strategy. Appl. Energy 2016, 164, 590-606.

103. Yu, J.; Jiao, Y.; Wang, X.; Cao, J.; Fei, S. Bi-level optimal dispatch in the Virtual Power Plant considering uncertain agents number. Neurocomputing 2015, 167, 551-557.

104. Zapata Riveros, J.; Bruninx, K.; Poncelet, K.; D’haeseleer, W. Bidding strategies for virtual power plants considering CHPs and intermittent renewables. Energy Convers. Manag. 2015, 103, 408-418.

105. Khodayar, M.E.; $\mathrm{Wu}, \mathrm{H}$. Demand forecasting in the smart grid paradigm: Features and challenges. Electr. J. 2015, 28, 51-62.

106. Dietrich, K.; Latorre, J.M.; Olmos, L.; Ramos, A. Modelling and assessing the impacts of self supply and market-revenue driven Virtual Power Plants. Electr. Power Syst. Res. 2015, 119, 462-470.

107. Wang, Q.; Zhang, C.; Ding, Y.; Xydis, G.; Wang, J.; Østergaard, J. Review of real-time electricity markets for integrating Distributed Energy Resources and Demand Response. Appl. Energy 2015, 138, 695-706.

108. Dabbagh, S.R.; Sheikh-El-Eslami, M.K. Risk-based profit allocation to DERs integrated with a virtual power plant using cooperative Game theory. Electr. Power Syst. Res. 2015, 121, 368-378.

109. Shabanzadeh, M.; Sheikh-El-Eslami, M.K.; Haghifam, M.R. The design of a risk-hedging tool for virtual power plants via robust optimization approach. Appl. Energy 2015, 155, 766-777.

110. Schäfer, M.; Gretzschel, O.; Schmitt, T.G.; Knerr, H. Wastewater treatment plants as system service provider for renewable energy storage and control energy in virtual power plants - A potential analysis. Energy Procedia 2015, 73, 87-93.

111. Zapata, J.; Vandewalle, J.; D'Haeseleer, W. A comparative study of imbalance reduction strategies for virtual power plant operation. Appl. Therm. Eng. 2014, 71, 847-857.

112. Pedersen, R.; Schwensen, J.; Biegel, B.; Stoustrup, J.; Green, T. Aggregation and control of supermarket refrigeration systems in a smart grid; IFAC, 2014; Vol. 19; ISBN 9783902823625.

113. Tascikaraoglu, A.; Erdinc, O.; Uzunoglu, M.; Karakas, A. An adaptive load dispatching and forecasting strategy for a virtual power plant including renewable energy conversion units. Appl. Energy 2014, 119, 445-453.

114. Othman, M.M.; Othman, M.M.; Hegazy, Y.G. A Review of Virtual power plant Definitions , Components , Framework and Optimization A Review of Virtual power plant Definitions, Components , Framework and Optimization. 2015, 6.

115. Moutis, P.; Hatziargyriou, N.D. Decision trees aided scheduling for firm power capacity provision by virtual power plants. Int. J. Electr. Power Energy Syst. 2014, 63, 730-739.

116. Faria, P.; Soares, T.; Vale, Z.; Morais, H. Distributed generation and demand response dispatch for a virtual power player energy and reserve provision. Renew. Energy 2014, 66, 686-695.

117. Sowa, T.; Krengel, S.; Koopmann, S.; Nowak, J. Multi-criteria operation strategies of power-to-heat-Systems in virtual power plants with a high penetration of renewable energies. Energy Procedia 2014, 46, 237-245.

118. Tajeddini, M.A.; Rahimi-Kian, A.; Soroudi, A. Risk averse optimal operation of a virtual power plant using two stage stochastic programming. Energy 2014, 73, 958-967.

119. Grobovoy, A.; Arestova, A.; Khmelik, M.; Shipilov, V.; Nikitin, Y. Smart grid technologies simulation experience at Russky Island; IFAC, 2014; Vol. 19; ISBN 9783902823625.

120. Arslan, O.; Karasan, O.E. Cost and emission impacts of virtual power plant formation in plug-in hybrid electric vehicle penetrated networks. Energy 2013, 60, 116-124.

121. Peik-Herfeh, M.; Seifi, H.; Sheikh-El-Eslami, M.K. Decision making of a virtual power plant under uncertainties for bidding in a day-ahead market using point estimate method. Int. J. Electr. Power Energy Syst. 2013, 44, 88-98. 
122. Pade, L.L.; Schröder, S.T. Fuel cell based micro-combined heat and power under different policy frameworks-An economic analysis. Energy Convers. Manag. 2013, 66, 295-303.

123. PandŽić, H.; Morales, J.M.; Conejo, A.J.; Kuzle, I. Offering model for a virtual power plant based on stochastic programming. Appl. Energy 2013, 105, 282-292.

124. Pandžić, H.; Kuzle, I.; Capuder, T. Virtual power plant mid-term dispatch optimization. Appl. Energy 2013, 101, 134-141.

125. Shropshire, D.; Purvins, A.; Papaioannou, I.; Maschio, I. Benefits and cost implications from integrating small flexible nuclear reactors with off-shore wind farms in a virtual power plant. Energy Policy 2012, 46, 558-573.

126. Kusch, W.; Schmidla, T.; Stadler, I. Consequences for district heating and natural gas grids when aiming towards 100\% electricity supply with renewables. Energy 2012, 48, 153-159.

127. Petersen, M.; Hansen, L.H.; Mølbak, T. Exploring the value of flexibility: A smart grid discussion. IFAC Proc. Vol. 2012, 8, 43-48.

128. Lombardi, P.; Sokolnikova, T.; Styczynski, Z.; Voropai, N. Virtual power plant management considering energy storage systems; IFAC, 2012; Vol. 8; ISBN 9783902823243.

129. de Souza, A.R.R.; Aoki, A.R.; Donadon, A.R.; Lambert-Torres, G.; da Silva, L.E.B.; Camargo, J.C. Virtual Power Plant Management considering Energy Storage Systems and Multiple Power Sources; IFAC, 2012; Vol. 45;

130. Sučić, S.; Dragičević, T.; Capuder, T.; Delimar, M. Economic dispatch of virtual power plants in an eventdriven service-oriented framework using standards-based communications. Electr. Power Syst. Res. 2011, $81,2108-2119$.

131. Wille-Haussmann, B.; Erge, T.; Wittwer, C. Decentralised optimisation of cogeneration in virtual power plants. Sol. Energy 2010, 84, 604-611.

132. Bakker, V.; Bosman, M.G.C.; Molderink, A.; Hurink, J.L.; Smit, G.J.M. Improved heat demand prediction of individual households. IFAC Proc. Vol. 2010, 1, 110-115.

133. Ausubel, L.M.; Cramton, P. Virtual power plant auctions. Util. Policy 2010, 18, 201-208.

134. Liang, Z.; Alsafasfeh, Q.; Jin, T.; Pourbabak, H.; Su, W. Risk-Constrained Optimal Energy Management for Virtual Power Plants Considering Correlated Demand Response. IEEE Trans. Smart Grid 2017, 3053, 1-11.

135. Zhang, G.; Jiang, C.; Wang, X. Comprehensive review on structure and operation of virtual power plant in electrical system. IET Gener. Transm. Distrib. 2018, 13, 145-156.

136. Xiao, L.; Lin, L.; Liu, Y. Discussions on the architecture and operation mode of future power grids. Energies 2011, 4, 1025-1035.

137. Yu, S.; Fang, F.; Liu, Y.; Liu, J. Uncertainties of virtual power plant: Problems and countermeasures. Appl. Energy 2019, 239, 454-470.

138. Luo, Z.; Hong, S.H.; Ding, Y.M. A data mining-driven incentive-based demand response scheme for a virtual power plant. Appl. Energy 2019, 239, 549-559.

139. Adu-Kankam, K.O.; Camarinha-Matos, L.M. Towards Collaborative Virtual Power Plants. Sustain. Energy, Grids Networks 2018, 28-39.

140. Moreno, B.; Díaz, G. The impact of virtual power plant technology composition on wholesale electricity prices: A comparative study of some European Union electricity markets. Renew. Sustain. Energy Rev. 2019, 99, 100-108.

141. Zhao, Z.; Luo, J.; Tian, S.; Gao, Y.; Yang, W.; Yang, Y. Optimal Operation Modes of Virtual Power Plants Based on Typical Scenarios Considering Output Evaluation Criteria. Energies 2018, 11, 2634.

142. Wang, X.; Li, H.; Ehsan, A.; Yang, W.; Duan, J.; Gao, Y.; Yang, Y. Multi-Objective Virtual Power Plant Construction Model Based on Decision Area Division. Appl. Sci. 2018, 8, 1484.

143. Pasetti, M.; Rinaldi, S.; Manerba, D. A Virtual Power Plant Architecture for the Demand-Side Management of Smart Prosumers. Appl. Sci. 2018, 8, 432.

144. Li, X.; Zhao, D.; Guo, B. Decentralized and Collaborative Scheduling Approach for Active Distribution Network with Multiple Virtual Power Plants. Energies 2018, 11, 3208.

145. Gong, J.; Xie, D.; Jiang, C.; Zhang, Y. Multiple objective compromised method for power management in virtual power plants. Energies 2011, 4, 700-716.

146. Bai, H.; Miao, S.; Ran, X.; Ye, C. Optimal dispatch strategy of a virtual power plant containing battery switch stations in a unified electricity market. Energies 2015, 8, 2268-2289. 
972

973

974

975

976

977

978

979

980

981

982

983

984

985

986

987

988

989

990

991

992

993

994

995

996

997

998

999

1000

1001

1002

1003

1004

1005

1006

1007
147. Gao, Y.; Cheng, H.; Zhu, J.; Liang, H.; Li, P. The optimal dispatch of a power system containing virtual power plants under fog and haze weather. Sustain. 2016, 8, 1-22.

148. Zhang, J.; Seet, B.C.; Lie, T.T. An event-based resource management framework for distributed decisionmaking in decentralized virtual power plants. Energies 2016, 9.

149. Cao, C.; Xie, J.; Yue, D.; Huang, C.; Wang, J.; Xu, S.; Chen, X. Distributed Economic Dispatch of Virtual Power Plant under a Non-Ideal Communication Network. Energies 2017, 10.

150. Kazmi, S.A.A.; Shahzad, M.K.; Khan, A.Z.; Shin, D.R. Smart distribution networks: A review of modern distribution concepts from a planning perspective; 2017; Vol. 10; ISBN 8201059476.

151. Ma, Z.; Billanes, J.D.; Jørgensen, B.N. Aggregation potentials for buildings-Business models of demand response and virtual power plants. Energies 2017, 10.

152. Qiu, J.; Zhao, J.; Wang, D.; Zheng, Y. Two-stage coordinated operational strategy for distributed energy resources considering wind power curtailment penalty cost. Energies 2017, 10.

153. Han, H.; Cui, H.; Gao, S.; Shi, Q.; Fan, A.; Wu, C. A remedial strategic scheduling model for load serving entities considering the interaction between grid-level energy storage and virtual power plants. Energies 2018, 11.

154. Li, P.; Tan, Q.; Ju, L.; De, G.; Tan, Z. A CVaR-Robust Risk Aversion Scheduling Model for Virtual Power Plants Connected with Wind-Photovoltaic-Hydropower-Energy Storage Systems, Conventional Gas Turbines and Incentive-Based Demand Responses. Energies 2018, 11, 2903.

155. Iacobucci, R.; McLellan, B.; Tezuka, T. The Synergies of Shared Autonomous Electric Vehicles with Renewable Energy in a Virtual Power Plant and Microgrid. Energies 2018, 11, 2016.

156. Gao, Y.; Zhou, X.; Ren, J.; Wang, X.; Li, D. Double layer dynamic game bidding mechanism based on multiagent technology for virtual power plant and internal distributed energy resource. Energies 2018, 11.

157. Wang, J.; Yang, W.; Cheng, H.; Huang, L.; Gao, Y. The optimal configuration scheme of the virtual power plant considering benefits and risks of investors. Energies 2017, 10.

158. Almadhor, A.; Krad, I. A Generation Driven Control Strategy in a Hybrid Micro grid with Mesh Networks using Virtual Power Plant Model. 2019 16th IEEE Annu. Consum. Commun. Netw. Conf. 1-6.

159. Cui, S.; Wang, Y.-W.; Lin, X.; Xiao, J.-W. Residential virtual power plant with photovoltaic output forecasting and demand response. Asian J. Control 2019, 1-12.

160. Shayegan Rad, A.; Badri, A.; Zangeneh, A.; Kaltschmitt, M. Risk-based optimal energy management of virtual power plant with uncertainties considering responsive loads. Int. J. Energy Res. 2019, 1-16.

161. Kasaei, M.J. Energy and operational management of virtual power plant using imperialist competitive algorithm. Int. Trans. Electr. Energy Syst. 2018, 28, 1-13.

162. Gerami Moghaddam, I. Scheduling a smart energy hub-based virtual power plant using benders decomposition to considering power system constraints. Int. Trans. Electr. Energy Syst. 2018, 28, 2-5.

163. Kahlen, M.T.; Ketter, W.; van Dalen, J. Electric Vehicle Virtual Power Plant Dilemma: Grid Balancing Versus Customer Mobility. Prod. Oper. Manag. 2018, 27, 2054-2070. 